\title{
Recommendations of the SFH (French Society of Haematology) for the diagnosis, treatment and follow-up of hairy cell leukaemia
}

\author{
Edouard Cornet • Alain Delmer • Pierre Feugier • Francine Garnache-Ottou • \\ David Ghez • Véronique Leblond • Vincent Levy • Frédéric Maloisel • \\ Daniel Re • Jean-Marc Zini • Xavier Troussard
}

Received: 7 May 2014 / Accepted: 16 June 2014 / Published online: 5 July 2014

(C) The Author(s) 2014. This article is published with open access at Springerlink.com

\begin{abstract}
Hairy cell leukaemia (HCL) is a rare haematological malignancy, with approximately 175 new incident cases in France. Diagnosis is based on a careful examination of the blood smear and immunophenotyping of the tumour cells, with a panel of four markers being used specifically to screen for hairy cells (CD11c, CD25, CD103 and CD123). In 2011, the $\mathrm{V} 600 \mathrm{E}$ mutation of the BRAF gene in exon 15 was identified in HCL; being present in HCL, it is absent in the variant form of HCL (HCL-v) and in splenic red pulp lymphoma (SRPL), two entities related to HCL. The management of patients with HCL has changed in recent years. A poorer response to purine nucleoside analogues (PNAs) is observed in patients with more marked leukocytosis, bulky splenomegaly, an unmutated immunoglobulin variable heavy chain (IgVH) gene profile, use of $\mathrm{VH} 4-34$ or with TP53 mutations. We present the recommendations of a group of 11 experts
\end{abstract}

E. Cornet $\cdot X$. Troussard $(\bowtie)$

Haematology Laboratory, Caen University Hospital, 14033 Caen Cedex, France

e-mail: troussard-x@chu-caen.fr

\section{A. Delmer}

Department of Clinical Haematology, Reims University Hospital, 51092 Reims Cedex, France

\section{P. Feugier}

Haematology Division, Nancy University Hospital, 54035 Nancy

Cedex, France

F. Garnache-Ottou

EFS, BFC, 25020 Besançon Cedex, France

D. Ghez

Gustave Roussy, 94805 Villejuif Cedex, France

V. Leblond

Department of Clinical Haematology, Pitié Salpêtrière Hospital,

75651 Paris Cedex, France belonging to a number of French hospitals. This group met in November 2013 to examine the criteria for managing patients with HCL. The ideas and proposals of the group are based on a critical analysis of the recommendations already published in the literature and on an analysis of the practices of clinical haematology departments with experience in managing these patients. The first-line treatment uses purine analogues: cladribine or pentostatin. The role of BRAF inhibitors, whether or not combined with MEK inhibitors, is discussed. The panel of French experts proposed recommendations to manage patients with HCL, which can be used in a daily practice.

Keywords Hairy cell leukaemia $\cdot$ Recommendations · Diagnosis · Treatment

V. Levy

Haematology Oncology Thorax Division, Hôpital Avicenne, 93003 Bobigny Cedex, France

\section{F. Maloisel}

Sainte Anne Clinic, 67085 Strasbourg Cedex, France

D. Re

Antibes Hospital, 06100 Nice Cedex, France

D. $\operatorname{Re}$

Antoine Lacassagne Centre (Nice), 06100 Nice Cedex, France

J.-M. Zini

Saint Louis Hospital, 75010 Paris Cedex, France

X. Troussard

Haematology Laboratory, CHU de Caen, 14000 Caen, France 


\section{Background}

The epidemiological data relating to hairy cell leukaemia (HCL) are limited. HCL is a rare haematological malignancy, representing $2 \%$ of all leukaemia [1]. Between 1992 and 2000, a review of 12 American databases covering $14 \%$ of the American population revealed a higher frequency of HCL among white Americans than among African Americans or Asians [2]. The data from the lower Normandy Regional Register of Haematological Malignancies indicate an incidence standardized to the world population of $0.29 \pm 0.08$ per 100,000 . The incidence is higher in men $(0.50 \pm 0.15)$ than in women $(0.12 \pm 0.008)$ [3]. These data, extrapolated to France, suggest approximately 175 incident cases of HCL per year.

The median age of patients at diagnosis is 52 (24-81). The SEER (Surveillance, Epidemiology and End Results Program; http://seer.cancer.gov) study conducted in 3,776 patients shows an improvement in survival over the calendar periods analysed (before 1984, 1984-1990, 1991-1999 and 20002008) and a reduction in the risk of mortality of $6.5 \%$ per year. The survival rate for HCL is lower among African Americans [4].

The causes of HCL remain unknown. The existence of familial forms suggests a genetic predisposition in some cases [1]. The role of certain environmental factors remains unclear; a risk associated with forage growing or exposure to organophosphate insecticides has been identified, as has a tobaccoassociated protective effect [5]. In 2011, mutations were identified in five genes (BRAF, CSMD3, SLC5A1, CNTN6 and $O R 8 J)$ by means of whole-exome high-throughput sequencing performed on the $(>90 \%) \mathrm{CD} 19^{+}$tumour cells from a patient with HCL and on the ( $>98 \%) \mathrm{CD}^{-}$mononuclear cells from the same patient at the time of remission [6]. The V600E mutation of the BRAF gene in exon 15 was confirmed by means of direct sequencing in 47 other patients with HCL. However, it was absent in 195 patients with another chronic B cell lymphoproliferative disorder, including patients with marginal zone lymphoma.

HCL may be associated with other haematological malignancies, particularly multiple myeloma (MM), large granular lymphocytic leukaemia (LGL) or chronic myeloid leukaemia (CML) [7].

\section{Diagnosis}

The circumstances under which the disease is discovered are related to the consequences of bone marrow suppression, including severe or recurrent infections, to the detection of splenomegaly, whether symptomatic or not, or to the often fortuitous identification of hairy cells during a routine blood count.
In all cases, the diagnosis is based on a careful examination of the blood smear and immunophenotyping of the tumour cells.

Identification of hairy cells in the blood smear

Hairy cells_-large cells with abundant, poorly demarcated, grey to weakly and irregularly basophilic cytoplasm - display fine cytoplasmic projections distributed around the entire circumference of the cell. "Granular/lamellar" cytoplasmic inclusions with the appearance of slightly basophilic rods with a clear central area are detected occasionally. The nucleus-tocytoplasm ratio is low, and the nucleus is often in an eccentric position. Oval or round, it can sometimes be kidney-shaped. The nuclear chromatin has a dispersed appearance and never coarse, and the nucleolus, which is not readily seen, is small and often solitary. Sometimes difficult to identify in a poor quality smear, the cells are found consistently in the blood smear, even if only in small numbers.

Monocytopenia is almost always present. It may be erroneously absent from the results yielded by automated haematology analysers, which regularly identify hairy cells as monocytes. There is no lymphocytosis. Neutropenia, anaemia that is often mildly macrocytic and thrombocytopenia of varying severity often complete the constellation of laboratory findings.

\section{Immunophenotype}

Immunophenotyping can be performed on blood or bone marrow. Hairy cells must be looked for within a large cell gate (in the vicinity of the monocyte gate).

It comprises an analysis of the B cell lineage markers (CD19, CD20) combined with a panel of markers used specifically to screen for hairy cells (CD11c, CD25, CD103, CD123) and screening for an immunoglobulin light chain isotype restriction.

The four markers CD11c, CD25, CD103 and CD123 define the HCL score [8], which distinguishes HCL from other B cell haematological disorders associated with hairy cells, including the variant form of HCL (HCL-v), splenic marginal zone lymphoma (SMZL) and splenic red pulp lymphoma (SRPL). One point is given to each marker when it is expressed, and no point is given when it is not expressed. A score of 3 or 4 is observed in $98 \%$ of cases of HCL, unlike with other B cell haematological disorders associated with hairy cells, where the score is usually 0 or 1 . It is not compulsory to calculate this score, the co-expression of the markers CD11c, CD25 and CD103 representing a sufficient basis on which to diagnose HCL. If a negative result is obtained for one of these three markers, there is a need to assess the expression of CD123 and to calculate this score. 
Although there is no need to calculate it for the diagnosis of HCL, the Royal Marsden Hospital (RMH) score [9] used in chronic lymphocytic leukaemia (CLL) is usually 0 or 1.

\section{Bone marrow examination}

This is not obligatory, except in clinical trials.

Where diagnosis proves difficult or immunophenotyping is inconclusive and the number of hairy cells present is small, a bone marrow biopsy combined with bone marrow aspiration is desirable. Hairy cells, cells which are easily recognizable by their oval or kidney-shaped nuclei, their chromatin pattern, the clear "halo" which separates the nuclei and the abundant cytoplasm which is difficult to see, have a typical "fried egg" appearance.

Immunohistochemistry (IHC) is sometimes useful for detecting hairy cells in limited numbers - expression of the isoenzyme 5 of tartrate acid-resistant phosphatase (TRAP) in the form of non-specific but characteristic granular cytoplasm positivity, expression of $\mathrm{CD} 20$ and CD72 and the mutated BRAF protein [10].

Cytogenetic and molecular analyses

Cytogenetic studies and $B R A F$ V600E mutation testing [6,11] are not necessary for diagnosis. $B R A F \mathrm{~V} 600 \mathrm{E}$ mutation testing may be useful in cases of diagnostic uncertainty and in cases where therapeutic management is complex.

Other investigations at diagnosis

Clinical evaluation must include the following:

- A patient history, looking for any familial history of haematological malignancy or autoimmune disorders;

- Identification of any systemic symptoms;

- Checking for signs of disease, especially checking for splenomegaly. The use of imaging can be helpful for this. Ultrasonography of the spleen can be used to measure the size of the spleen and to identify abdominal lymphadenopathy, which is uncommon.

Biological tests include the following:

- A complete blood count with differential including a reticulocyte count;

- Serum protein electrophoresis to look for a monoclonal component;

- Haemolysis screen in the presence of suspicion.

The following is desirable:

- Preservation of tumour material in blood and/or bone marrow before any treatment.

\section{Differential diagnosis}

The variant form of HCL and SRPL constitutes forms which are difficult to diagnose with areas of overlap with HCL [12].

Variant form of HCL

Despite being described as long ago as 1980 [13], the variant form of HCL (HCL-v) is a rare entity $(10 \%$ of all cases of HCL). The terminology is ambiguous, because it is a disorder distinct from HCL. It affects men, with a median age of 71 years (48-92 years) [14,15]. Monocytopenia is absent, and leukocytosis is $>10 \times 10^{9} / \mathrm{L}$ in more than $90 \%$ of cases. Examination of the blood smear shows a proliferation of hairy cells (20-95\% of the lymphoid cells) of medium to large size with a large and clearly visible nucleolus and condensed chromatin. There is infiltration of the splenic red pulp. The HCL score is low $(0,1$ or 2$)$ with a strong expression of CD11c (87 \%) and CD103 (60\%) contrasting with a weak, rare expression of CD123 (7\%) or CD25 (6\%) $[15,16]$. The $B R A F$ V600E mutation is absent.

Splenic red pulp lymphoma or SRPL

SRPL is rare [17] and was described recently. It affects men (sex ratio, 1.64) with a median age of 77 years (46-91). In three quarters of cases, lymphocytosis is present and examination of the blood smear shows the presence of a proliferation of hairy cells (median, $60 \%$; 26-91 \% of the lymphoid cells) of small to medium size with, in the majority of cells, a small or invisible nucleolus. The cellular phenotype is very heterogeneous, quite close to HCL-v, with a strong expression of CD11c (97\%), a variable expression of CD103 (38\%) and little or no expression of CD123 (16\%) and CD25 (3\%). The blood karyotype may show anomalies such as $7 \mathrm{q}$ deletion. The immunoglobulin variable heavy chain $(\mathrm{IgVH})$ gene profile is mutated in $80 \%$ of cases, with over-represented use of VH3-26 and VH4-34. The BRAF V600E mutation is absent in SRPL.

\section{Required pretreatment evaluation}

Assessment of prognostic factors

Unless there is a therapeutic indication, there is no justification for carrying out any additional investigations for the assessment of prognostic factors. No prognostic factor will modify the choice of first-line treatment, which is based on purine nucleoside analogues (PNAs): cladribine or pentostatin. 
Studies in patients treated with cladribine have resulted in the identification of factors, which may reduce the following responses to treatment:

- Leukocytosis $>10 \times 10^{9} / \mathrm{L}[18]$

- Bulky spleen extending $>10 \mathrm{~cm}$ below costal margin [18]

- Unmutated $I g V H$ gene profile $\geq 98 \%$ [18]

- Use of the VH4-34 repertoire [19]

- Mutation of the TP53 gene [18].

Other factors reduce event-free survival (EFS) [18] as follows:

- Bulky spleen extending $>10 \mathrm{~cm}$ below costal margin

- Elevated levels of circulating hairy cells $>10 \times 10^{9} / \mathrm{L}$

- Unmutated $I g V H$ profile.

TP53 mutation testing and analysis of the IgVH gene repertoire to test for VH4-34 positivity must be performed in the event of a relapse, before the second line of treatment, on previously frozen material or fresh material if possible.

\section{Pretreatment assessment}

Parameters considered necessary for a complete pretreatment evaluation may differ depending on whether or not the patient is treated in a clinical protocol.

The following are essential pretreatment tests (clinical trials and general practice):

- Physical examination including the determination of the performance status as defined by the Eastern Cooperative Oncology Group (ECOG) and the identification of comorbidities and potential sites of infection.

- Serum chemistry including creatinine with calculation of creatinine clearance (Modification of Diet in Renal Disease (MDRD) Study), haemolysis screen (direct antiglobulin test, haptoglobin, unconjugated bilirubin and lactic dehydrogenase) and liver function tests (transaminases) with hepatitis B and C serology (risk of reactivation after immunosuppressive therapy).

- Preservation of cells and serum in a tumour bank is recommended.

- Chest radiograph and abdominal and pelvic imaging.

The following are additional pretreatment tests that may be performed in clinical trials:

- Blood and bone marrow karyotypes analysis.

- BRAF V600E mutation testing.

- Mutational status of $\operatorname{IgVH}$ gene and analysis of the $\mathrm{VH}$ gene usage.

- Mutational status of TP53 gene.

\section{Treatment}

Indications for treatment

Criteria for initiating treatment may vary depending on whether or not the patient is treated in a clinical trial. In general practice, treatment is indicated in the presence of at least one of the signs of active disease as follows:

1. Symptomatic splenomegaly

2. Cytopenia (involving at least one cell type)

(a) Haemoglobin $<10 \mathrm{~g} / \mathrm{dL}$

(b) Platelets $<100 \times 10^{9} / \mathrm{L}$

(c) Neutrophils $<1 \times 10^{9} / \mathrm{L}$

3. Recurrent or severe infections

In the absence of treatment, clinical monitoring and monitoring of the blood count are necessary every 3 months for the first year and then every 6 months.

Treatment strategy

Inclusion in a prospective study protocol is recommended. In general practice, the recommendations are as follows.

\section{First-line treatment}

The first-line treatment is based on PNAs [20-22]: cladribine or pentostatin. The different dosing regimens for the two medicinal products are listed in Table 1.

There are no data in the literature proving the superiority of one drug over the other. The choice between pentostatin and cladribine is based essentially on the presence or absence of renal impairment, the severity of the cytopenias and the dosing regimens of the products. Cladribine may be used intravenously (IV) or subcutaneously (SC), unlike pentostatin, which is used only via the IV route. The SC form offers ease of administration and the option of treatment on an outpatient basis, unlike cladribine IV.

In the presence of renal impairment (plasma creatinine clearance (MDRD) $<60 \mathrm{~mL} / \mathrm{min}$ ), pentostatin is contraindicated owing to limited experience, unlike cladribine.

\section{Special cases}

In cases of severe neutropenia (neutrophil count $<0.2 \times 10^{9} / \mathrm{L}$ ) and/or uncontrolled active infection, the treatment of choice is interferon via the $\mathrm{SC}$ route at a dose of 3 million units $\times 3$ per week followed by a purine analogue once the neutropenia has been corrected. Another option, although not validated in this indication, is the use of rituximab on its own at a dose of $375 \mathrm{mg} / \mathrm{m}^{2}$ IV for 4 weeks in the place of interferon. 
Table 1 Different dosing regimens

Dosing regimen for cladribine (2-chlorodeoxyadenosine (2-CDA))

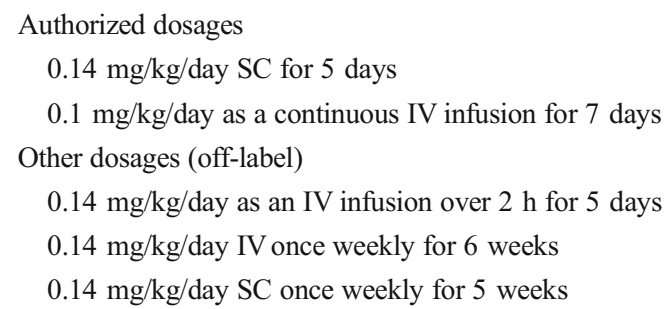

The dosage must be repeated in the absence of CR at 6 months

Dosing regimen for pentostatin in HCL (2'-deoxycoformycin ( 2 '-DCF))

$4 \mathrm{mg} / \mathrm{m}^{2}$ every 2 weeks until a maximal response is achieved, plus one or two additional injections

Determine the creatinine clearance before each administration and avoid the medicinal product in the presence of clearance $<60 \mathrm{~mL} /$ $\min$

Dosing regimen for rituximab (4-8 doses in total)

$375 \mathrm{mg} / \mathrm{m}^{2}$ IV once weekly administered simultaneously or sequentially with the purine analogue in patients without $\mathrm{CR}$ after a single treatment with pentostatin or cladribine

Interferon alpha (IFN- $\alpha)$

$3 \times 10^{6} \mathrm{U}$ SC daily until a maximal response is achieved and continuation at the same dose three times weekly. In very cytopenic patients, start on a dose of $3 \times 10^{6} \mathrm{U} 3$ times weekly

Splenectomy

Indicated in cases of bulky splenomegaly $(>10 \mathrm{~cm}$ below the costal margin) and in cases of moderate bone marrow involvement, after immunization programme
In cases of early relapse $(<24$ months), the diagnosis of HCL must be confirmed and BRAF V600E mutation testing must be performed.

1. If the diagnosis of HCL is confirmed, the management approach will depend on the presence or absence of a TP53 gene mutation and VH4-34 use.

(a) In the absence of the TP53 gene mutation, with a VH repertoire other than VH4-34, the use of a PNA combined with rituximab is recommended.

(b) In cases of TP53 gene mutation [25] and/or use of VH4-34, the different treatment options are as follows:

- Immunotoxins, but they are not available in France [26,27].

- BRAF inhibitors either alone or in combination with MEK inhibitors. No treatment regimen is defined at present [28-31]. The use of these treatments must take into account the toxicity of these drugs, including their cutaneous effects [30,32,33].

- Bendamustine and rituximab in combination [34].

- If access to innovative compounds is impossible, a combination of treatment with PNA and rituximab is recommended.

2. If the diagnosis of HCL is not confirmed and in the absence of a BRAF V600E mutation, an analysis of the $\mathrm{IgVH}$ repertoire to test for $\mathrm{VH} 4-34$ use must be performed. Treatment must be considered on a case-by-case basis.

In cases of active haemolytic anaemia, consideration might be given to rituximab.

In cases of pregnancy, the only treatment that can be used is interferon via the $\mathrm{SC}$ route at a dose of 3 million units $\times 3$ per week.

In cases of two co-existing haematological disorders or a concomitant haematological disorder, the management approach should be discussed at a multidisciplinary meeting.

\section{Relapses}

Only symptomatic relapses require treatment.

First relapse In cases of late relapse ( $>60$ months), PNAs may be used again. No recommendations exist regarding whether or not the PNAs should be changed.

In cases of intermediate relapse (24-60 months), the second-line treatment also relies on PNAs, whether or not a different PNA is used and whether or not it is combined with rituximab, administered concomitantly or sequentially (nonvalidated treatment regimens) $[23,24]$.
Subsequent relapses Some options used before the era of PNAs should not be ruled out, including splenectomy and interferon.

\section{Prevention of infectious complications}

The prevention of infectious complications occurring during the course of HCL treatment or in the post-treatment period is of prime importance.

In the prevention of Pneumocystis jiroveci-induced infections with Bactrim ${ }^{\circledR}$ until recovery of $\mathrm{T}$ cell numbers to CD4 $>200 / \mathrm{mm}^{3}$, there is an increased risk of allergic skin reactions during concomitant use of Bactrim ${ }^{\circledR}$ with purine analogues. This risk can be reduced by starting Bactrim ${ }^{\circledR}$ 1 week after the purine analogue. In cases of allergy to Bactrim ${ }^{\circledR}$ or cytopenias potentially linked to Bactrim ${ }^{\circledR}$, Pentacarinat ${ }^{\circledR}$ or atovaquone (Wellvone ${ }^{\circledR}$ ) aerosols may be used.

Prevention of zoster infections with aciclovir or valaciclovir should also be started 1 week after PNAs. The optimal duration of prophylaxis has not been determined. 
Growth factors should be considered on a case-by-case basis.

No data in the literature provide a basis for either recommending or not recommending the irradiation of labile blood products after treatment with purine analogues.

\section{Response criteria and evaluation}

The following definitive response should be assessed:

- For pentostatin, at the end of treatment, after 8 to 10 cycles

- For cladribine, 3 to 6 months after the end of treatment.

Complete remission $(\mathrm{CR})$ is defined as follows:

- Recovery of blood counts with haemoglobin $>12 \mathrm{~g} / \mathrm{dL}$, platelets $>150 \times 10^{9} / \mathrm{L}$, neutrophils $>1.5 \times 10^{9} / \mathrm{L}$ and absence of circulating hairy cells

- Regression of splenomegaly

- Absence of hairy cells on the bone marrow biopsy specimen, including IHC analyses (CD20, CD72).

In the absence of a bone marrow biopsy specimen, a very good response (VGR) is defined as recovery of the blood counts (haemoglobin $>12 \mathrm{~g} / \mathrm{dL}$, platelets $>150 \times 10^{9} / \mathrm{L}$, neutrophils $>1.5 \times 10^{9} / \mathrm{L}$ and absence of circulating hairy cells) and regression of splenomegaly.

A partial response (PR) is defined as a poorer quality haematological response, with persistence of splenomegaly, cytopenias or presence of circulating hairy cells on blood smear analysis.

In cases of PR, the treatment approach depends on the desired objective.

If quality of life is a priority (elderly subject, comorbidities), regular haematological monitoring (clinical examination and complete blood count) every 6 months should be recommended.

If response quality is sought (young subject), achieving complete remission (CR) is desirable. CR should be defined as a negative bone marrow biopsy, including IHC, and ideally minimal residual disease (MRD) which is undetectable in the blood and/or bone marrow by means of flow cytometry. The impact of detectable MRD on the risks of relapse and on prognosis remains unknown, however [35,36]. In the absence of CR, a new treatment, either with the same PNA or with a combination of cladribine and rituximab, is recommended.

Conflict of interest The authors declare that they have no conflict of interest.
Open Access This article is distributed under the terms of the Creative Commons Attribution License which permits any use, distribution, and reproduction in any medium, provided the original author(s) and the source are credited.

\section{References}

1. Bernstein L, Newton P, Ross RK (1990) Epidemiology of hairy cell leukemia in Los Angeles County. Cancer Res 50(12):3605-3609

2. Morton L, Wang S, Devesa S, Hartge P, Weisenburger D, Linet M (2006) Lymphoma incidence patterns by who subtype in the United States, 1992-2001. Blood 107(1):265-276. doi:10.1182/Blood2005-06-2508

3. Troussard X, Duchenet V, Cornet E, Mouchel D, Malet M, Collignon A (2009) Haematological malignancies: incidence in BasseNormandie, France, for 1997-2004. Rev Epidemiol Sante Publique 57(3):151-158. doi:10.1016/J.Respe.2009.02.204

4. Chandran R, Gardiner SK, Smith SD, Spurgeon SE (2013) Improved survival in hairy cell leukaemia over three decades: a seer database analysis of prognostic factors. Br J Haematol 163(3):407-409. doi: 10.1111/Bjh. 12490

5. Clavel J, Hemon D, Mandereau L, Delemotte B, Severin F, Flandrin G (1996) Farming, pesticide use and hairy-cell leukemia. Scand J Work Environ Health 22(4):285-293

6. Tiacci E, Trifonov V, Schiavoni G, Holmes A, Kern W, Martelli MP, Pucciarini A, Bigerna B, Pacini R, Wells VA, Sportoletti P, Pettirossi V, Mannucci R, Elliott O, Liso A, Ambrosetti A, Pulsoni A, Forconi F, Trentin L, Semenzato G, Inghirami G, Capponi M, Di Raimondo F, Patti C, Arcaini L, Musto P, Pileri S, Haferlach C, Schnittger S, Pizzolo G, Foa R, Farinelli L, Haferlach T, Pasqualucci L, Rabadan R, Falini B (2011) BRAF mutations in hairy-cell leukemia. N Engl J Med 364(24):2305-2315. doi:10.1056/Nejmoa1014209

7. Gopaluni S, Sanyal S, Bair A, Vajpayee N (2011) Hairy cell leukemia variant in a patient with chronic myeloid leukemia receiving nilotinib: sequential or coincidental? J Clin Oncol. doi:10.1200/Jco. 2011.38.1392

8. Matutes E, Morilla R, Owusu-Ankomah K, Houliham A, Meeus P, Catovsky D (1994) The immunophenotype of hairy cell leukemia (HCL). Proposal for a scoring system to distinguish HCL from B-cell disorders with hairy or villous lymphocytes. Leuk Lymphoma 14(Suppl 1):57-61

9. Matutes E, Owusu-Ankomah K, Morilla R, Garcia Marco J, Houlihan A, Que T, Catovsky D (1994) The immunological profile of B-cell disorders and proposal of a scoring system for the diagnosis of CLL. Leukemia 8(10):1640-1645

10. Andrulis M, Penzel R, Weichert W, Von Deimling A, Capper D (2012) Application of a BRAF V600E mutation-specific antibody for the diagnosis of hairy cell leukemia. Am J Surg Pathol 36(12): 1796-1800. doi:10.1097/Pas.0b013e3182549b50

11. Blombery PA, Wong SQ, Hewitt CA, Dobrovic A, Maxwell EL, Juneja S, Grigoriadis G, Westerman DA (2012) Detection of BRAF mutations in patients with hairy cell leukemia and related lymphoproliferative disorders. Haematologica 97(5):780-783. doi:10.3324/ Haematol.2011.054874

12. Summers TA, Jaffe ES (2011) Hairy cell leukemia diagnostic criteria and differential diagnosis. Leuk Lymphoma 52(Suppl 2):6-10. doi: 10.3109/10428194.2011.565435

13. Cawley JC, Burns GF, Hayhoe FG (1980) A chronic lymphoproliferative disorder with distinctive features: a distinct variant of hairycell leukaemia. Leuk Res 4(6):547-559

14. Robak T (2011) Hairy-cell leukemia variant: recent view on diagnosis, biology and treatment. Cancer Treat Rev 37(1):3-10. doi:10. 1016/J.Ctrv.2010.05.003 
15. Matutes E, Wotherspoon A, Catovsky D (2003) The variant form of hairy-cell leukaemia. Best Pract Res Clin Haematol 16(1):41-56

16. Shao H, Calvo KR, Gronborg M, Tembhare PR, Kreitman RJ, Stetler-Stevenson M, Yuan CM (2013) Distinguishing hairy cell leukemia variant from hairy cell leukemia: development and validation of diagnostic criteria. Leuk Res. doi:10.1016/J. Leukres.2012.11.021

17. Traverse-Glehen A, Baseggio L, Bauchu EC, Morel D, Gazzo S, Ffrench M, Verney A, Rolland D, Thieblemont C, Magaud JP, Salles G, Coiffier B, Berger F, Felman P (2008) Splenic red pulp lymphoma with numerous basophilic villous lymphocytes: a distinct clinicopathologic and molecular entity? Blood 111(4):2253-2260. doi:10.1182/ Blood-2007-07-098848

18. Forconi F, Sozzi E, Cencini E, Zaja F, Intermesoli T, Stelitano C, Rigacci L, Gherlinzoni F, Cantaffa R, Baraldi A, Gallamini A, Zaccaria A, Pulsoni A, Gobbi M, Tassi M, Raspadori D, Leoncini L, Rinaldi A, Sabattini E, Bertoni F, Pileri SA, Lauria F (2009) Hairy cell leukemias with unmutated IGHV genes define the minor subset refractory to single-agent cladribine and with more aggressive behavior. Blood 114(21):4696-4702. doi:10.1182/Blood-2009-03-212449

19. Arons E, Suntum T, Stetler-Stevenson M, Kreitman RJ (2009) VH4$34+$ hairy cell leukemia, a new variant with poor prognosis despite standard therapy. Blood 114(21):4687-4695. doi:10.1182/Blood2009-01-201731

20. Else M, Dearden CE, Matutes E, Garcia-Talavera J, Rohatiner AZ, Johnson SA, O'Connor NT, Haynes A, Osuji N, Forconi F, Lauria F, Catovsky D (2009) Long-term follow-up of 233 patients with hairy cell leukaemia, treated initially with pentostatin or cladribine, at a median of 16 years from diagnosis. Br J Haematol 145(6):733-740. doi:10.1111/J.1365-2141.2009.07668.X

21. Jones G, Parry-Jones N, Wilkins B, Else M, Catovsky D (2012) Revised guidelines for the diagnosis and management of hairy cell leukaemia and hairy cell leukaemia variant*. Br J Haematol 156(2): 186-195. doi:10.1111/J.1365-2141.2011.08931.X

22. Kreitman RJ, Polliack A, Grever M (2011) Treatment of hairy cell leukemia in its second half-century: an international conference on hairy cell leukemia at the National Institutes of Health, April 26-27, 2010, Bethesda, MD. Leuk Lymphoma 52(Suppl 2):1-2. doi:10. 3109/10428194.2011.552478

23. Cervetti G, Galimberti S, Andreazzoli F, Fazzi R, Cecconi N, Caracciolo F, Petrini M (2008) Rituximab as treatment for minimal residual disease in hairy cell leukaemia: extended follow-up. Br J Haematol 143(2):296-298. doi:10.1111/J.1365-2141.2008.07333.X

24. Zenhausern R, Simcock M, Gratwohl A, Hess U, Bargetzi M, Tobler A, Swiss Group For Clinical Cancer R (2008) Rituximab in patients with hairy cell leukemia relapsing after treatment with 2chlorodeoxyadenosine (SAKK 31/98). Haematologica 93(9):14261428. doi:10.3324/Haematol.11564

25. Forconi F, Cencini E, Sicuranza A, Sozzi E, Lauria F (2011) Molecular insight into the biology and clinical course of hairy cell leukemia utilizing immunoglobulin gene analysis. Leuk Lymphoma 52(1):15-23. doi:10.3109/10428194.2010.530362

26. Kreitman RJ, Tallman MS, Robak T, Coutre S, Wilson WH, StetlerStevenson M, Fitzgerald DJ, Lechleider R, Pastan I (2012) Phase I trial of anti-CD22 recombinant immunotoxin moxetumomab pasudotox (CAT-8015 or HA22) in patients with hairy cell leukemia. J Clin Oncol. doi:10.1200/Jco.2011.38.1756

27. Kreitman RJ, Arons E, Stetler-Stevenson M, Fitzgerald DJ, Wilson WH, Pastan I (2011) Recombinant immunotoxins and other therapies for relapsed/refractory hairy cell leukemia. Leuk Lymphoma 52(Suppl 2):82-86. doi:10.3109/10428194. 2011.565843

28. Dietrich S, Glimm H, Andrulis M, Von Kalle C, Ho AD, Zenz T (2012) BRAF inhibition in refractory hairy-cell leukemia. N Engl J Med 366(21):2038-2040. doi:10.1056/Nejmc1202124

29. Follows GA, Sims H, Bloxham DM, Zenz T, Hopper MA, Liu H, Bench A, Wright P, Van't Veer MB, Scott MA (2013) Rapid response of biallelic BRAF V600E mutated hairy cell leukaemia to low dose vemurafenib. Br J Haematol 161(1):150-153. doi:10.1111/Bjh. 12201

30. Lacouture ME, O'Reilly K, Rosen N, Solit DB (2012) Induction of cutaneous squamous cell carcinomas by RAF inhibitors: cause for concern? J Clin Oncol 30(3):329-330. doi:10.1200/Jco.2011.38. 2895

31. Peyrade F, Re D, Ginet C, Gastaud L, Allegra M, Ballotti R, Thyss A, Zenz T, Auberger P, Robert G (2013) Low-dose vemurafenib induces complete remission in a case of hairy-cell leukemia with a V600E mutation. Haematologica 98(2):E20-22. doi:10.3324/Haematol. 2012.082404

32. Anforth R, Fernandez-Penas P, Long GV (2013) Cutaneous toxicities of RAF inhibitors. Lancet Oncol 14(1):E11-18. doi:10.1016/S14702045(12)70413-8

33. Su F, Viros A, Milagre C, Trunzer K, Bollag G, Spleiss O, Reis-Filho JS, Kong X, Koya RC, Flaherty KT, Chapman PB, Kim MJ, Hayward R, Martin M, Yang H, Wang Q, Hilton H, Hang JS, Noe J, Lambros M, Geyer F, Dhomen N, Niculescu-Duvaz I, Zambon A, Niculescu-Duvaz D, Preece N, Robert L, Otte NJ, Mok S, Kee D, Ma Y, Zhang C, Habets G, Burton EA, Wong B, Nguyen H, Kockx M, Andries L, Lestini B, Nolop KB, Lee RJ, Joe AK, Troy JL, Gonzalez R, Hutson TE, Puzanov I, Chmielowski B, Springer CJ, McArthur GA, Sosman JA, Lo RS, Ribas A, Marais R (2012) RAS mutations in cutaneous squamous-cell carcinomas in patients treated with BRAF inhibitors. N Engl J Med 366(3):207-215. doi:10.1056/ Nejmoa1105358

34. Burotto M, Stetler-Stevenson M, Arons E, Zhou H, Wilson W, Kreitman RJ (2013) Bendamustine and rituximab in relapsed and refractory hairy cell leukemia. Clin Cancer Res 19(22):6313-6321. doi:10.1158/1078-0432.Ccr-13-1848

35. Sigal DS, Sharpe R, Burian C, Saven A (2010) Very long-term eradication of minimal residual disease in patients with hairy cell leukemia after a single course of cladribine. Blood 115(10):18931896. doi:10.1182/Blood-2009-10-251645

36. Ravandi F, Jorgensen JL, O'Brien SM, Verstovsek S, Ca K, Faderl S, Giles FJ, Ferrajoli A, Wierda WG, Odinga S, Huang $\mathrm{X}$, Thomas DA, Freireich EJ, Jones D, Keating MJ, Kantarjian HM (2006) Eradication of minimal residual disease in hairy cell leukemia. Blood 107(12):4658-4662. doi:10.1182/Blood-2005$11-4590$ 